\title{
Effects of feeding restriction and meal pattern of a sugar beet- containing diet and control diet on nutrient digestibility, plasma lipid concentrations and postprandial triacylglycerol response in broiler chickens
}

\author{
BY A. RAZDAN AND D. PETTERSSON \\ Department of Food Science, Swedish University of Agricultural Sciences, \\ S-750 07 Uppsala, Sweden
}

(Received 22 January 1993 - Revised 13 May 1993 - Accepted 8 June 1993)

\begin{abstract}
Broiler chickens were fed on a control diet based on maize or a diet containing sugar-beet-pulp fibre (Beetfiber) at an inclusion level of $46 \mathrm{~g} / \mathrm{kg}$. Diets were provided ad lib. or at a restricted level either once daily or three times daily. On days 13 and 20, chickens fed on the ad lib. control and sugar-beet-pulpcontaining diets generally weighed more and had poorer feed conversion ratios than chickens given the restricted control and sugar-beet-pulp-containing diets respectively. Furthermore, chickens given the restricted diets once daily had greater body weights and generally improved feed conversion efficiencies compared with chickens given the restricted diets three times daily. Generally, elevated plasma lipid concentrations were observed amongst chickens given the restricted diets once daily compared with chickens fed ad lib. as well as the restricted diets three times daily, while chickens fed on restricted diets three times daily had plasma lipid concentrations intermediate between those fed $a d$ lib. and once daily. In a plasma triacylglycerol response study on day 22, feeding of sugar-beet-pulp-containing diets generally reduced postprandial triacylglycerol concentrations and delayed triacylglycerol response relative to chickens given the control diets either $a d$ lib. or restricted, which may indicate gastrointestinal adaptation to feeding of a fibre-rich diet. Postprandial triacylglycerol concentrations observed for chickens receiving restricted diets were increased compared with chickens given the respective ad lib. diets, indicating adaptation of chickens to reduced feed frequency. On day 25, feeding of sugar-beetpulp-containing diets decreased digesta dry matter content and ileal organic matter digestibility. Chickens given sugar-beet-pulp-containing diets generally had, on day 25, increased caecal short-chain fatty acid (SCFA) concentrations in comparison with chickens given the ad lib. control diet, indicating increased fermentation of dietary components. It is also noteworthy that the greatest SCFA concentrations were observed amongst chickens given the control diet once daily, suggesting enhanced caecal fermentation capacity. This may have been a consequence of increased bacterial activity and caecal hypertrophy due to infrequent feeding of a low-fibre diet.
\end{abstract}

Sugar beet: Plasma lipids: Dietary fibre: Feeding frequency: SCFA: Chickens

Hyperlipidaemia is considered a major risk factor in the development of cardiovascular disease (Anderson \& Tietyen-Clark, 1986). In recent years the search for dietary means to reduce blood lipid levels as a more desirable alternative to expensive drug therapy has focused research efforts on the effects of dietary fibre on lipid metabolism (Anderson et al. 1990; Furda, 1990).

The relative solubility of dietary fibres in water has a profound influence on their effect on lipid metabolism; water-soluble dietary fibres including pectins have well established plasma cholesterol-reducing properties (Chang, 1983; Kritchevsky, 1986). Sugar-beet fibre (Beetfiber) contains approximately $250 \mathrm{~g}$ soluble dietary fibre $/ \mathrm{kg}$, of which the major part 
is pectin, and has been shown to reduce blood triacylglycerol and total plasma cholesterol concentrations in chickens (Pettersson \& Razdan, 1993).

Reduced meal frequency or intermittent feeding (i.e. one to two meals daily) is associated with a range of physiological and metabolic effects in animals including stomach and small intestine hypertrophy, increased postprandial plasma insulin levels and enhanced cholesterol synthesis in the liver (Fábry \& Tepperman, 1970). Restricted feeding of a lowfibre diet once daily to broiler chickens resulted in a three-fold increase in blood triacylglycerol concentrations in comparison with chickens given a low-fibre diet ad lib. (Pettersson \& Razdan, 1993). In studies on normal human subjects, increasing meal frequency has been shown to reduce significantly fasting total plasma cholesterol, lowdensity lipoprotein and apolipoprotein B concentrations (Jenkins et al. 1989), while in another study nibbling diets given to non-insulin diabetics reduced significantly plasma triacylglycerol concentrations relative to meals provided three times daily (Jenkins et al. 1992).

The present experiment was conducted in order to establish the effects on production results and plasma lipid concentrations in broiler chickens fed on a control diet supplemented with sugar-beet fibre given either $a d$ lib., once daily or three times daily. Ileal digestibility, triacylglycerol concentrations over a $6 \mathrm{~h}$ postprandial period and caecal shortchain fatty acid (SCFA) concentration in broiler chickens given diets ad lib. or once daily were also analysed.

MATERIALS AND METHODS

Sugar-beet pulp

Standard dried sugar-beet pulp (Beetfiber) was supplied by the Swedish Sugar Company, Arlöv, Sweden.

\section{Diets}

The chickens received a control diet based on maize $(405 \mathrm{~g} / \mathrm{kg}$ feed), or isonitrogenous diets in which part of the maize starch, fish meal, meat-and-bone meal, and animal fat components were substituted with sugar-beet pulp at an inclusion level of $46 \mathrm{~g} / \mathrm{kg}$ feed (Table 1). Lysine and DL-methionine were included at a level of $1 \mathrm{~g} / \mathrm{kg}$ in each of the mash diets, milled to pass a $3.5 \mathrm{~mm}$ screen.

\section{Chickens}

A total of 384 1-d-old broiler chickens (Ross) of mixed sex were divided into twenty-four groups of sixteen chickens with an average group weight of $600 \mathrm{~g}$ and a maximum difference in weight of $4 \mathrm{~g}$ between groups. The groups were randomly allotted to six fourtier battery cages with raised wire floors in a windowless, light- and temperature-controlled room. The six experimental diets were randomly assigned to four replicates (cages) each. Chickens were wing banded and their sex determined on day 1 of the experiment. Chickens fed on the ad lib. control (C) and sugar-beet-pulp-containing (BP) diets had free access to feed and water except for $8 \mathrm{~h}$ before collection of serum samples for analysis of plasma cholesterol and triacylglycerol concentrations on days 14 and 21 . Chickens fed on the restrictive diets were on days 4-21 given $0 \cdot 8$ of the average total feed intake of the chickens fed on ad lib. C or BP diets respectively. Chickens restrictively fed on C and BP diets were fed once daily at 24.00 hours (C-1 and BP-1 diets respectively) except on occasions before blood collection when feed was given at 22.00 hours. Chickens given the C-3 and BP-3 diets received the same quantity of feed as chickens given the C-1 and BP-1 diets respectively, but the feed was divided into three portions which were given to the chickens on three separate occasions each day at 08.00, 16.00 and 24.00 hours (C-3 and BP-3 diets, 
Table 1. Composition of the control and sugar-beet-pulp-containing broiler chicken diets ( $\mathrm{g} / \mathrm{kg}$ air dry basis)

\begin{tabular}{lcc}
\hline \multicolumn{1}{c}{ Diets ... } & Control & $\begin{array}{c}\text { Sugar-beet } \\
\text { pulp }\end{array}$ \\
Maize & $405 \cdot 0$ & $405 \cdot 0$ \\
Soya-bean meal & $200 \cdot 0$ & $200 \cdot 0$ \\
Fish meal & 40.5 & $37 \cdot 8$ \\
Meat-and-bone meal & $40 \cdot 5$ & $37 \cdot 8$ \\
Animal fat & $18 \cdot 8$ & $18 \cdot 8$ \\
Sugar-beet pulp & - & $46 \cdot 0$ \\
Maize starch & $246 \cdot 2$ & $207 \cdot 6$ \\
Limestone & $17 \cdot 0$ & $17 \cdot 0$ \\
Monocalcium phosphate & $13 \cdot 0$ & $13 \cdot 0$ \\
Vitamin and trace element premix* & $10 \cdot 0$ & $10 \cdot 0$ \\
Salt & $3 \cdot 0$ & $3 \cdot 0$ \\
Cholesterol & $2 \cdot 0$ & $2 \cdot 0$ \\
Lysine hydrochloride & $1 \cdot 0$ & $1 \cdot 0$ \\
DL-Methionine & $1 \cdot 0$ & $1 \cdot 0$ \\
\hline \hline
\end{tabular}

* For details of composition, see Pettersson \& Åman (1992).

respectively). However, the third portion of feed was given at 22.00 hours on occasions before culling.

\section{Production study}

Individual chicken weights and group cumulative feed intake (air-dry weight) were recorded at 13 and $20 \mathrm{~d}$ of age and group feed conversion ratios ( $\mathrm{g}$ feed/g weight-gain) were calculated on a weight-gain basis.

\section{Plasma lipid study}

At both days 14 and 21, chickens were starved overnight ( $8 \mathrm{~h}$ from 24.00 hours) after which two birds from each cage (one of each sex) with weights as close as possible to the average group weight were slaughtered by cervical dislocation. Blood samples were collected from the jugular veins of each chicken for plasma triacylglycerol and cholesterol analyses.

\section{Postprandial plasma triacylglycerol study}

After blood sampling for the plasma lipid study on day 21 , dietary restrictions were removed and diets were given $a d$ lib. (from 15.00 hours) to all remaining chickens. On day 22 , chickens fed on the ad lib. C and BP diets as well as the C-1 and BP-1 restricted diets up to this point of the experiment were starved for $3 \mathrm{~h}$ after which one chicken from two of the four cages from each diet was chosen randomly and slaughtered by cervical dislocation (at 08.00 hours). Blood samples were collected from the jugular veins of the animals for analysis of fasting plasma triacylglycerols. The remaining chickens involved in this part of the experiment were then given their respective diets $a d$ lib. for a $1 \mathrm{~h}$ period and feed intake was recorded. After this, one chicken from two of the four cages from each diet was chosen randomly and slaughtered by cervical dislocation, and blood samples were collected as described immediately after feed was removed following the $1 \mathrm{~h}$ feeding period (09.00 hours). Further culling occurred at $2,3,4,5$ and $6 \mathrm{~h}$ after feed was provided. At each cull, one randomly selected chicken from two of the four cages from each diet was killed. Blood samples were collected from each culled chicken at the specified times. At the end of the study, three chickens from each of the remaining two cages from each diet were 
relocated to cages previously occupied by chickens used in the triacylglycerol response study in order to replenish numbers for the digestibility study on day 25 .

\section{Digestibility study}

From 15.00 hours on day 22, diets were given ad lib. with a marker $\left(\mathrm{Cr}_{2} \mathrm{O}_{3}\right)$ incorporated at a level of $4 \mathrm{~g} / \mathrm{kg}$. On day 25 , one randomly selected bird from each of the cages containing chickens previously given the $a d$ lib. C and BP diets as well as the C-1 and BP1 restricted diets was slaughtered by cervical dislocation. Thereafter, slaughtering occurred every fourth hour for a further $20 \mathrm{~h}$. At each slaughter the gastrointestinal tracts of the chickens were quickly removed and the contents of the last third of the small intestine (denoted ileum) were collected separately, pooled for each group, frozen $\left(-25^{\circ}\right)$ and freeze-dried. Digestibilities in the digesta samples were calculated relative to the $\mathrm{Cr}_{2} \mathrm{O}_{3}$ marker.

\section{Chemical analysis}

All analyses were carried out in duplicate and results are reported on a dry matter basis. Before analysis, representative feed samples were ground in a Cyclotec 1093 sample mill (Tecator AB, Höganäs, Sweden) to pass a $0.5 \mathrm{~mm}$ screen. Samples of freeze-dried digesta were ground in a Retsch mill $(0.5 \mathrm{~mm}$ screen size). Dry matter was determined by oven drying at $105^{\circ}$ for $16 \mathrm{~h}$. Ash and crude protein $(\mathrm{N} \times 6.25)$ were analysed according to standard methods of the Association of Official Analytical Chemists (1984). Crude fat was extracted with diethyl ether in a Tecator Soxtec System HT after $3 \mathrm{M}-\mathrm{HCl}$ acid-hydrolysis (Anon, 1971). Starch was determined enzymically (Åman \& Hesselman, 1984). Total dietary fibre, defined as the sum of non-starch polysaccharides and Klason lignin was analysed according to the method of Theander \& Westerlund (1986). $\mathrm{Cr}_{2} \mathrm{O}_{3}$ was determined as described by Fenton \& Fenton (1979). Caecal samples were extracted in 50 mu-Tris- $\mathrm{HCl}$ buffer ( $\mathrm{pH} 6.5$ ) to a sample concentration of $1 \mathrm{mg} / \mathrm{ml}$ and analysis of caecal SCFA was performed by HPLC. A filtrate $(20 \mu \mathrm{l})$ of the sample medium was injected onto a Biorad Amnex HPX-87H column at $60^{\circ}$ with a flow-rate of $0.4 \mathrm{ml}$ eluent $\left(0.05 \mathrm{M}-\mathrm{H}_{2} \mathrm{SO}_{4}\right) / \mathrm{min}$, and the refractive index was measured using a Tecator RI 5902 refractometer (Kjell Larsson, personal communication).

Plasma was isolated from blood samples by centrifugation $(200 \mathrm{~g})$ and triacylglycerol, total cholesterol and high-density lipoprotein (HDL) concentrations were analysed using enzymic colorimetric kits (Boehringer Mannheim Diagnostica).

\section{Calculations and statistical analysis}

Statistical analysis of the registered variables (production results, plasma triacylglycerol and cholesterol concentrations, and ileal digestibility values) was performed by an analysis of variance procedure, the general linear model (GLM) supported by the statistical analysis system (Statistical Analysis Systems Institute Inc., 1985). In the statistical model, the main effects of diet (individual diets; ad lib.-fed C and BP, C-1, C-3, BP-1 and BP-3), feeding regimen ( ad lib. or restricted), class of diet ( $\mathrm{C}$ or BP-diet) and time (bird age or time after feeding) were considered. The effect of sex was not considered when analysing production variables since these results are presented as cage means and live weights were not influenced by the effect of sex.

\section{RESULTS}

Diets

The content of starch accounted for $520 \mathrm{~g} / \mathrm{kg}$ dry matter of the $\mathrm{C}$ diet while the content in the BP diet was approximately $480 \mathrm{~g} / \mathrm{kg}$ (Table 2 ). The contents of crude protein, crude fat 
Table 2. Chemical composition ( $\mathrm{g} / \mathrm{kg}$ dry matter) of the control and sugar-beet-pulpcontaining broiler chicken diets

\begin{tabular}{lcc}
\hline & Control diet & $\begin{array}{c}\text { Sugar-beet-pulp- } \\
\text { containing diet }\end{array}$ \\
\hline Starch & $522 \cdot 0$ & $483 \cdot 6$ \\
Crude protein & $182 \cdot 8$ & $186 \cdot 4$ \\
Crude fat (HCl) & $55 \cdot 6$ & $54 \cdot 1$ \\
Ash & $72 \cdot 7$ & $76 \cdot 6$ \\
Non-starch polysaccharide residues & & $20 \cdot 2$ \\
$\quad$ Arabinose & $12 \cdot 3$ & $15 \cdot 6$ \\
Xylose & $16 \cdot 2$ & $41 \cdot 0$ \\
Glucose & $42 \cdot 4$ & $28 \cdot 3$ \\
Uronic acids & $15 \cdot 9$ & $7 \cdot 0$ \\
Klason lignin & $7 \cdot 0$ & $138 \cdot 6$ \\
Total dietary fibre & $115 \cdot 7$ & \\
\hline
\end{tabular}

and ash were similar between the $\mathrm{C}$ and BP diets. The sum of non-starch polysaccharide residues accounted for approximately 120 and $140 \mathrm{~g} / \mathrm{kg}$ dry matter content of the $\mathrm{C}$ and $\mathrm{BP}$ diets respectively and the predominant non-starch polysaccharide residues were arabinose, xylose, glucose and uronic acids. Levels of arabinose and uronic acid residues in the $\mathrm{BP}$ diet were 1.6 and 1.8 times greater respectively than in the $\mathrm{C}$ diet.

\section{Production study}

The mortality for the entire experiment was $1 \%$ and was not significantly influenced by individual diet, feeding regimen, class of diet or bird age.

Over the whole experimental period, broiler chicken live weights and feed intakes were significantly influenced by feeding regimen $(P<0.05)$. Feed conversion ratio was affected by both diet and feeding regimen $(P=0 \cdot 001)$.

Restricted feeding reduced body weight on days 13 and 20 (Table 3 ). Improved feed conversion ratios were generally observed amongst chickens given the restricted diets compared with chickens given the ad lib. diets.

\section{Plasma lipid study}

Plasma triacylglycerol concentrations were influenced $(P=0.001)$ by individual diet and feeding regimen and bird age. Total plasma cholesterol concentrations were influenced by diet, feeding regimen and class of $\operatorname{diet}(P=0.001)$ while plasma HDL concentrations were affected $(P=0 \cdot 001)$ by diet and feeding regimen.

Triacylglycerol concentrations were generally higher at day 14 in comparison with those observed at day 21 . In general, decreasing feed frequency of the restricted diets increased plasma lipid concentrations compared with the ad lib.-fed diets in their respective dietary classes (Table 4). The greatest concentrations of plasma lipids were observed amongst chickens given the $\mathrm{C}-1$ and $\mathrm{BP}-1$ restricted diets. It is also noteworthy that ad lib. feeding of the BP diet resulted in the lowest plasma triacylglycerol concentrations.

At day 14, increased plasma triacylglycerol concentrations were observed amongst chickens given the $\mathrm{C}-1$ and BP-1 diets in comparison with those of birds given the ad lib. diets. Ad lib. feeding of the BP diet significantly reduced total plasma cholesterol concentrations compared with the BP-1 diet as well as all control diets. In addition, on day 14, plasma HDL-cholesterol concentrations amongst chickens given the ad lib. BP diet 
Table 3. Live weight, cumulative feed intake and feed conversion ratio of broiler chickens receiving control $(C)$ or sugar-beet-pulp-containing $(B P)$ diets*

(Means for sixty-four chickens)

\begin{tabular}{|c|c|c|c|c|c|c|c|}
\hline \multirow[t]{3}{*}{ Diet... } & \multicolumn{3}{|c|}{$\mathrm{C}$} & \multicolumn{3}{|c|}{$\mathrm{BP}$} & \multirow{3}{*}{$\begin{array}{l}\text { Pooled } \\
\text { SEM }\end{array}$} \\
\hline & \multirow[b]{2}{*}{ ad lib. } & \multicolumn{2}{|c|}{ Restricted $\dagger$} & \multirow[b]{2}{*}{ ad lib. } & \multicolumn{2}{|c|}{ Restricted $\dagger$} & \\
\hline & & C-1 & C-3 & & BP-1 & $\mathrm{BP}-3$ & \\
\hline \multicolumn{8}{|l|}{ Body wt (g) } \\
\hline Day 13 & $224^{\mathrm{a}}$ & $205^{b}$ & $200^{\mathrm{be}}$ & $208^{\mathrm{ab}}$ & $183^{\text {ed }}$ & $182^{\mathrm{d}}$ & $6 \cdot 2$ \\
\hline Day 20 & $451^{\mathrm{a}}$ & $399^{\text {bd }}$ & $394^{\mathrm{bc}}$ & $422^{\mathrm{ab}}$ & $372^{\mathrm{ed}}$ & $366^{\mathrm{c}}$ & $11 \cdot 1$ \\
\hline \multicolumn{8}{|c|}{ Cumulative feed intake (g) } \\
\hline Day 13 & $288^{\mathrm{a}}$ & $233^{\mathrm{b}}$ & $234^{\mathrm{b}}$ & $254^{c}$ & $206^{\mathrm{d}}$ & $206^{\mathrm{d}}$ & $6 \cdot 0$ \\
\hline Day 20 & $657^{\mathrm{a}}$ & $526^{\mathrm{b}}$ & $527^{\mathrm{b}}$ & $608^{c}$ & $487^{d}$ & $487^{\mathrm{d}}$ & $11 \cdot 5$ \\
\hline \multicolumn{8}{|l|}{$\begin{array}{l}\text { Feed conversion ratio } \\
\text { ( } \mathrm{g} \text { feed/g wt gain) }\end{array}$} \\
\hline Day 13 & $1 \cdot 57^{\mathrm{a}}$ & $1 \cdot 40^{\mathrm{b}}$ & $1 \cdot 44^{\mathrm{b}}$ & $1 \cdot 50^{\mathrm{ab}}$ & $1 \cdot 43^{\mathrm{b}}$ & $1 \cdot 43^{b}$ & 0.041 \\
\hline Day 20 & $1 \cdot 60^{\mathrm{a}}$ & $1 \cdot 46^{\mathrm{b}}$ & $1 \cdot 48^{b}$ & $1 \cdot 59^{\mathrm{a}}$ & $1 \cdot 46^{\mathrm{b}}$ & $1 \cdot 49^{b}$ & 0.032 \\
\hline
\end{tabular}

a,b.c.d Mean values within a row with unlike superscript letters were significantly different $(P<0.05)$.

C-1, BP-1, restricted diet given once daily; C-3, BP-3, restricted diet given three times daily.

* For details of diets and procedures, See Table 1 and pp. 390-391.

$\dagger$ From days 4 to 20 of the experiment the feed restriction corresponded to 0.8 of the feed given to chickens receiving the ad lib.-fed diets.

were significantly reduced relative to the birds receiving the C-1, BP-1 and C-3 restricted diets.

On day 21 only the plasma triacylglycerol concentrations of chickens given the C-1 diet were significantly greater than those of chickens given other diets, and chickens fed on the ad lib. $\mathrm{C}$ diet had significantly reduced total plasma cholesterol concentrations relative to those birds receiving the C- 1 and C-3 restricted diets. Restricted feeding of the C-1 diet at day 21 resulted in significantly increased plasma HDL-cholesterol concentrations compared with concentrations amongst chickens fed on the ad lib. C diet but not the C-3 restricted diet. Chickens given the $a d$ lib. BP diet had significantly reduced $(P<0.05)$ plasma HDLcholesterol concentrations compared with chickens receiving both restricted $\mathrm{C}$ and $\mathrm{BP}$ diets, although not in comparison with those chickens given the ad lib. $\mathrm{C}$ diet.

\section{Postprandial plasma triacylglycerol study}

Feed intakes for the $1 \mathrm{~h}$ feeding period were on average 8.3 (range 7.7-8.9) $\mathrm{g}$ feed per chicken for chickens fed on the C, C-1, BP and BP-1 diets and no significant differences in feed intake between diets were observed. Plasma triacylglycerol concentration during the triacylglycerol response study was influenced by time-period after feeding $(P=0.008)$ and class of diet $(P=0.05)$.

Chickens fed on control diets before the triacylglycerol response study were observed to have increased plasma triacylglycerol concentrations immediately after feed was removed $1 \mathrm{~h}$ after feeding commenced (Table 5) in comparison with chickens fed on BP diets. The greatest plasma triacylglycerol concentrations for chickens given the BP diet ad lib. and BP1 restricted diets were observed at 2 and $3 \mathrm{~h}$ after feed was given respectively. The greatest postprandial triacylglycerol response was observed amongst chickens given the $\mathrm{C}$-1 restricted diet $2 \mathrm{~h}$ after feeding and plasma triacylglycerol concentrations were significantly elevated at 1 and $2 \mathrm{~h}$ after feed provision in comparison with chickens given other types of diet. The greatest plasma triacylglycerol concentration amongst chickens previously 
Table 4. Plasma triacylglycerol, total plasma cholesterol concentrations, high-densitylipoprotein $(H D L)$-cholesterol and HDL: total plasma cholesterol ratio of broiler chickens receiving control $(C)$ or sugar-beet-pulp-containing $(B P)$ diets*

(Means for eight chickens)

\begin{tabular}{|c|c|c|c|c|c|c|c|}
\hline \multirow[t]{3}{*}{ Diet... } & \multicolumn{3}{|c|}{$\mathrm{C}$} & \multicolumn{3}{|c|}{ BP } & \multirow{3}{*}{$\begin{array}{l}\text { Pooled } \\
\text { SEM }\end{array}$} \\
\hline & \multirow[b]{2}{*}{$a d l i b}$. & \multicolumn{2}{|c|}{ Restricted $\dagger$} & \multirow[b]{2}{*}{ ad lib. } & \multicolumn{2}{|c|}{ Restricted $\dagger$} & \\
\hline & & $\mathrm{C}-1$ & $\mathrm{C}-3$ & & BP-1 & BP-3 & \\
\hline \multicolumn{8}{|l|}{ Day 14} \\
\hline Triacylglycerols (mM) & $0.45^{\mathrm{a}}$ & $1 \cdot 69^{\mathrm{c}}$ & $1 \cdot 05^{\mathrm{b}}$ & $0 \cdot 35^{\mathrm{a}}$ & $1 \cdot 40^{\mathrm{bc}}$ & $1 \cdot 04^{\mathbf{b}}$ & $0 \cdot 177$ \\
\hline \multicolumn{8}{|l|}{ Plasma cholesterol (mM) } \\
\hline Total & $5 \cdot 72^{\mathrm{a}}$ & $6 \cdot 52^{\mathrm{a}}$ & $6 \cdot 14^{\mathrm{a}}$ & $3.89^{b}$ & $6 \cdot 42^{a}$ & $5 \cdot 20^{\mathrm{ab}}$ & 0.479 \\
\hline HDL & $2.75^{\mathrm{ab}}$ & $3 \cdot 21^{\mathrm{a}}$ & $3 \cdot 07^{\mathrm{a}}$ & $2 \cdot 47^{b}$ & $3 \cdot 16^{\mathrm{a}}$ & $2 \cdot 82^{\mathrm{ab}}$ & $0 \cdot 210$ \\
\hline HDL: total cholesterol & 0.53 & 0.51 & 0.52 & 0.64 & 0.50 & 0.54 & 0.047 \\
\hline \multicolumn{8}{|l|}{ Day 21} \\
\hline Triacylglycerols (mM) & $0.57^{\mathrm{a}}$ & $1 \cdot 10^{\mathrm{b}}$ & $0.52^{\mathrm{a}}$ & $0 \cdot 24^{\mathrm{a}}$ & $0.58^{\mathrm{a}}$ & $0.43^{a}$ & $0 \cdot 140$ \\
\hline \multicolumn{8}{|l|}{ Plasma cholesterol (mM) } \\
\hline Total & $5 \cdot 31^{\mathrm{a}}$ & $6 \cdot 48^{b}$ & $6 \cdot 50^{\mathrm{b}}$ & $5 \cdot 34^{\mathrm{a}}$ & $6.04^{\mathrm{ab}}$ & $5 \cdot 68^{\mathrm{ab}}$ & $0 \cdot 364$ \\
\hline HDL & $2 \cdot 49^{a c}$ & $3.04^{\mathrm{b}}$ & $2 \cdot 95^{\mathrm{ab}}$ & $2 \cdot 31^{\mathrm{c}}$ & $2 \cdot 87^{\mathrm{ab}}$ & $2 \cdot 81^{\mathrm{ab}}$ & $0 \cdot 176$ \\
\hline HDL: total cholesterol & 0.47 & 0.48 & 0.46 & 0.46 & 0.47 & 0.49 & 0.036 \\
\hline
\end{tabular}

a.b.c Mean values within a row with unlike superscript letters were significantly different $(P<0.05)$.

C-1, BP-1, restricted diet given once daily; C-3, BP-3, restricted diet given three times daily.

* For details of diets and procedures, See Table 1 and pp. 390-392.

$\dagger$ From days 4 to 20 of the experiment the feed restriction corresponded to $0 \cdot 8$ of the feed given to chickens receiving the ad lib.-fed diets.

Table 5. Plasma triacylglycerol concentrations $(\mathrm{mM})$ of broiler chickens receiving control $(C)$ or sugar-beet-pulp-containing (BP) diets over a 6 h sampling period after a 3 h fasting period* (Means for two chickens)

\begin{tabular}{|c|c|c|c|c|c|}
\hline \multirow[t]{2}{*}{ Diet ... } & \multicolumn{2}{|c|}{$\mathrm{C}$} & \multicolumn{2}{|c|}{ BP } & \multirow[b]{2}{*}{$\begin{array}{l}\text { Pooled } \\
\text { SEM }\end{array}$} \\
\hline & ad lib. & $\begin{array}{c}\text { Restricted } \dagger \\
\text { C-1 }\end{array}$ & ad lib. & $\begin{array}{c}\text { Restricted } \dagger \\
\text { BP-1 }\end{array}$ & \\
\hline \multicolumn{6}{|c|}{ Time interval after feeding (h) } \\
\hline $0 \ddagger$ & $0 \cdot 84$ & 0.70 & 0.62 & $0 \cdot 50$ & $0 \cdot 149$ \\
\hline 1 & $0 \cdot 46^{\mathrm{a}}$ & $2 \cdot 30^{\mathrm{b}}$ & $0.97^{\mathrm{a}}$ & $1 \cdot 23^{\mathrm{a}}$ & $0 \cdot 277$ \\
\hline 2 & $1 \cdot 44^{\mathrm{ab}}$ & $1.73^{b}$ & $1 \cdot 12^{\mathrm{a}}$ & $0.96^{\mathrm{a}}$ & 0.137 \\
\hline 3 & $0 \cdot 77^{\mathrm{a}}$ & $1 \cdot 00^{\mathrm{a}}$ & $0.86^{\mathrm{a}}$ & $1 \cdot 64^{\mathrm{b}}$ & $0 \cdot 225$ \\
\hline 4 & 0.45 & 0.46 & 0.44 & 0.54 & $0 \cdot 140$ \\
\hline 5 & $0 \cdot 54$ & $0 \cdot 42$ & $0 \cdot 31$ & 0.46 & $0 \cdot 125$ \\
\hline 6 & 0.81 & 0.49 & $0 \cdot 44$ & $0 \cdot 32$ & $0 \cdot 167$ \\
\hline
\end{tabular}

${ }^{\mathrm{a}, \mathrm{b}}$ Mean values within a row with unlike superscript letters were significantly different $(P<0.05)$.

$\mathrm{C}-1, \mathrm{BP}-1$, restricted diet given once daily.

* For details of diets and procedures, see Table 1 and pp. 390-392.

$\uparrow$ From days 4 to 20 of the experiment the feed restriction corresponded to 0.8 of the feed given to the chickens receiving the ad lib.-fed diets.

$\mp$ Blood sample taken after a $3 \mathrm{~h}$ fast. 
Table 6. Digesta dry matter content $(\mathrm{g} / \mathrm{kg})$ and apparent ileal digestibility of nutrients and non-starch polysaccharide residues in the last third of the small intestine of broiler chickens receiving control $(C)$ or sugar-beet-pulp-containing $(B P)$ diets*

(Means for twenty-four chickens)

\begin{tabular}{|c|c|c|c|c|c|}
\hline \multirow[t]{2}{*}{ Diet... } & \multicolumn{2}{|c|}{$\mathrm{C}$} & \multicolumn{2}{|c|}{$\mathrm{BP}$} & \multirow[b]{2}{*}{$\begin{array}{l}\text { Pooled } \\
\text { SEM }\end{array}$} \\
\hline & ad lib. & $\begin{array}{c}\text { Restricted }+ \\
\text { C-1 }\end{array}$ & ad lib. & $\begin{array}{c}\text { Restricted } \dagger \\
\text { BP-1 }\end{array}$ & \\
\hline $\begin{array}{l}\text { Digesta dry matter content } \\
\text { Ileal digestibility }\end{array}$ & $225^{\mathrm{a}}$ & $235^{\mathrm{b}}$ & $188^{\mathrm{c}}$ & $184^{\mathrm{c}}$ & $2 \cdot 9$ \\
\hline Crude protein $(\mathrm{N} \times 6.25)$ & 0.79 & 0.80 & 0.79 & $0 \cdot 80$ & 0.006 \\
\hline Crude fat & $0 \cdot 82$ & 0.84 & $0 \cdot 81$ & $0 \cdot 80$ & $0 \cdot 011$ \\
\hline Starch & $0.97^{a}$ & $0 \cdot 98^{\mathrm{b}}$ & $0 \cdot 96^{c}$ & $0 \cdot 97^{\mathrm{a}}$ & 0.003 \\
\hline Organic matter & $0 \cdot 79^{\mathrm{a}}$ & $0 \cdot 80^{a}$ & $0.73^{b}$ & $0.75^{\mathrm{b}}$ & 0.004 \\
\hline \multicolumn{6}{|l|}{$\begin{array}{l}\text { Non-starch polysaccharide } \\
\text { residues }\end{array}$} \\
\hline Arabinose & -0.06 & -0.04 & $0 \cdot 02$ & -0.05 & 0.034 \\
\hline Xylose & $-0 \cdot 11^{\mathrm{ab}}$ & $0.05^{\mathrm{a}}$ & $-0.23^{b}$ & $-0.07^{\mathrm{ab}}$ & 0.076 \\
\hline Glucose & $0 \cdot 46^{\mathrm{a}}$ & $0 \cdot 48^{a}$ & $0 \cdot 18^{b}$ & $0 \cdot 19^{\mathrm{b}}$ & 0.066 \\
\hline Uronic acids & 0.03 & $0 \cdot 05$ & $0 \cdot 06$ & 0.28 & $0 \cdot 130$ \\
\hline Total dietary fibre & $0-30^{\mathrm{ab}}$ & $0.35^{\mathrm{a}}$ & $0 \cdot 15^{c}$ & $0 \cdot 22^{\mathrm{be}}$ & 0.029 \\
\hline
\end{tabular}

a,b,c Mean values within a row with unlike superscript letters were significantly different $(P<0 \cdot 05)$.

C-1, BP-1, restricted diet given once daily.

* For details of diets and procedures, see Table 1 and pp. 390-392.

$\dagger$ From days 4 to 20 of the experiment the feed restriction corresponded to 0.8 of the feed given to the chickens receiving the ad lib.-fed diets.

receiving the BP-1 restricted diet occurred $3 \mathrm{~h}$ after feedings and was significantly elevated in comparison with plasma triacylglycerol concentrations of birds fed the ad lib. BP diet as well as chickens given control diets.

\section{Digestibility study}

The ileal digesta dry matter content was significantly influenced $(P=0.001)$ by diet as well as class of diet. Individual diet and feeding regimen significantly affected $(P=0.001$ and $P=0.006$ respectively) the ileal digestibility of starch while individual diet and class of diet influenced $(P<0.01)$ ileal organic matter digestibility. The ileal digestibilities of glucose residues and total dietary fibre were both influenced by individual and class of diet $(P<0 \cdot 01)$.

Chickens given BP diets were observed to have significantly reduced $(P<0.05)$ ileal organic matter digestibility in comparison with chickens receiving control diets (Table 6). BP diets significantly reduced $(P<0.05)$ total dietary fibre digestibility in comparison with that of chickens receiving the $\mathrm{C}$ diets. Digesta dry matter content was increased amongst chickens given the C-1 restricted diet in comparison with the ad lib.-fed C diet as well as the BP diets, and feeding of BP diets generally reduced ileal dry matter content compared with the $\mathrm{C}$ diets. Feeding of BP diets generally reduced ileal digestibility of glucose residues and feeding of the BP-1 restricted diet increased (although not significantly) uronic acid digestibility in comparison with the ad lib. BP diet. Chickens fed on the BP-1 restricted diet also had increased ileal total dietary fibre digestibility compared with chickens given the $a d$ lib. BP diet.

Generally, numerical although not significant differences in caecal SCFA concentration 
Table 7. Short-chain fatty acid content ( $\mathrm{mg} / \mathrm{g}$ dry matter) of caecal digesta from broiler chickens receiving control $(C)$ or sugar-beet-pulp-containing $(B P)$ diets for $25 d^{*}$

\begin{tabular}{|c|c|c|c|c|c|}
\hline \multirow[t]{2}{*}{ Diet... } & \multicolumn{2}{|c|}{$\mathrm{C}$} & \multicolumn{2}{|c|}{$\mathrm{BP}$} & \multirow[b]{2}{*}{$\begin{array}{l}\text { Pooled } \\
\text { SEM }\end{array}$} \\
\hline & ad lib. & $\begin{array}{l}\text { Restricted } \dagger \\
\text { C-1 }\end{array}$ & ad lib. & $\begin{array}{c}\text { Restricted } \dagger \\
\text { BP-1 }\end{array}$ & \\
\hline \multicolumn{6}{|c|}{ Short-chain fatty acids } \\
\hline Acetic acid & $15 \cdot 3$ & $18 \cdot 7$ & $17 \cdot 2$ & $15 \cdot 9$ & 1.53 \\
\hline Propionic acid & 1.9 & $4 \cdot 1$ & $2 \cdot 5$ & $2 \cdot 5$ & $1 \cdot 42$ \\
\hline Butyric acid & $2 \cdot 6^{a}$ & $5 \cdot 4^{b}$ & $3 \cdot 7^{a b}$ & $4 \cdot 0^{\mathrm{ab}}$ & 0.65 \\
\hline
\end{tabular}

${ }^{\mathrm{a}, \mathrm{b}}$ Mean values within a row with unlike superscript letters were significantly different $(P<0.05)$.

C-1, BP-1, restricted diet given once daily.

* For details of diets and procedures, see Table 1 and pp. 390-392.

$\dagger$ From days 4 to 20 of the experiment the feed restriction corresponded to 0.8 of the feed given to the chickens receiving the ad lib.-fed diets.

were observed between chickens given the various diets. The greatest caecal SCFA concentrations were observed amongst chickens given the $\mathrm{C}-1$ restricted diet (Table 7). Birds receiving this diet had increased concentrations of acetic and propionic acids in comparison with chickens given other diets, and significantly increased $(P<0.05)$ butyric acid concentrations in comparison with chickens given the ad lib. C diet. SCFA concentrations were not significantly different between chickens given the ad lib. BP and BP-1 restricted diets, although SCFA concentrations amongst chickens given BP diets were generally increased in comparison with concentrations amongst chickens receiving the ad lib. C diet.

\section{DISCUSSION}

In the present experiment, chickens fed on the ad lib. BP diet generally had lower body weights and feed intakes, improved feed conversion ratio, reduced plasma lipid concentrations, reduced postprandial triacylglycerol response and reduced ileal digestibility of organic matter compared with birds fed on the ad lib. C diet. Decreasing meal frequency and feed intake of control as well as BP-containing diets generally reduced body weight and feed conversion ratio and elevated plasma lipid concentrations. It is noteworthy that the effects of reduced meal frequency were largely offset by the inclusion of sugar-beet pulp in the diet.

Water-soluble pectins have been shown to delay gastric emptying in rats (Chang, 1983) and humans (Sandhu et al. 1987) probably as a result of increased viscosity and distension of the duodenum (Sellers, 1977); the resulting increase in satiety may also account for the reduced feed intake and growth rate of chickens fed on ad lib. BP diets in the present experiment. Furthermore, dietary pectins, by virtue of their relatively high water-holding capacity (Michel et al. 1988), tend to increase viscosity in the small intestine (Graham et al. 1986). The reduced ileal dry matter content of chickens fed on BP diets in this experiment was probably due to the increased water-holding capacity of the pectins. It is possible that viscous fibres act as barriers to diffusion and absorption of nutrients in the small intestine, including dietary fat in the form of micelles (Vahouny \& Cassidy, 1986), or that dietary fibres entrap or sequester bile acids and in so doing increase faecal sterol excretion (Furda, 1990). Interruption of enterohepatic circulation increases hepatic bile acid synthesis from cholesterol, thus lowering the pool of plasma low-density lipoprotein (LDL) and total 
cholesterol (Lampe et al. 1991) which is in agreement with the observed reduction in plasma total cholesterol concentrations amongst chickens fed on the ad lib. BP diet in the present study. Plasma triacylglycerol concentrations of chickens receiving the C-1 and BP-1 diets were elevated approximately three-fold in comparison with chickens given the $a d$ lib. $\mathrm{C}$ and BP diets respectively on day 14 . Studies on meal frequency in rats (Fábry \& Kujalová, 1960) have shown that animals adapt to periods of reduced meal frequency by gorging feed, which results in enlargement of the gastrointestinal tract. In human studies, an increased postprandial secretion of insulin (Jenkins et al. 1989) and increased lipogenesis have been observed and these factors can presumably be related directly to the degree of meal restriction. Insulin mediates lipoprotein lipase (EC 3.1.1.34; LPL) and is consequently associated with enhanced lipoprotein metabolism (O'Looney \& Vahouny, 1987). Hydrolysis of triacylglycerol-rich lipoproteins by LPL yields free triacylglycerols which can be taken up by extrahepatic cells (Cryer, 1987). Moreover, LPL hydrolysis of chylomicrons and very-low-density lipoproteins (VLDL) results in the formation of HDL in normal adults, normal children and diabetics (Quinn et al. 1982). Elevated triacylglycerol and HDL concentrations on days 14 and 21 of chickens fed on diets once daily in the present experiment may be an indication, therefore, of an adaptive increase in the hydrolysis of triacylglycerol-rich lipoproteins. Additionally, increased postprandial secretion of insulin as a result of gorging may account for increased LPL activity which would be related to increased postprandial plasma triacylglycerol concentrations amongst chickens given diets once daily on day 22 .

Certain dietary fibres are understood to have lipid-reducing effects (Furda, 1990). Viscous dietary fibres have been shown to increase the apparent thickness of the unstirred boundary layer in vitro (Johnson \& Gee, 1981) as well as in vivo (Dietschy et al. 1971) and impede the rate of glucose uptake from gut sections in man (Flourie et al. 1984). Postprandial levels of dietary triacylglycerols of chickens fed on the ad lib. BP diet were reduced in comparison with plasma triacylglycerol concentrations amongst chickens fed on the ad lib. $\mathrm{C}$ diet, indicating that diffusion of triacylglycerols may be impaired by the viscous pectins. It may be assumed, therefore, that micelles or mixed micelles would be subject to similar restrictions of diffusion accounting for the generally reduced postprandial plasma lipid concentrations observed amongst chickens given the ad lib. BP diet compared with chickens given the $a d l i b$. $\mathrm{C}$ diet in the present experiment. Although uptake of lipids may have been restricted by the presence of viscous pectins, there was no significant evidence obtained to suggest that this was caused by a reduced ileal digestibility of crude fat.

The increased postprandial triacylglycerol response by chickens receiving the $\mathrm{C}-1$ restricted diet compared with chickens given the ad lib. $\mathrm{C}$ diet may indicate a degree of intestinal adaptation. It is noteworthy that chickens given the ad lib. BP diet had a reduced plasma triacylglycerol response in comparison with chickens given the ad lib. C diet which may be attributed, once more, to enhanced viscosity from the pectins from the BP diet. Plasma triacylglycerol concentrations amongst chickens fed on the BP-1 restricted diet were elevated several hours after feeding suggesting that pectins delayed gastric emptying despite the meal restriction and, therefore, effectively assisted in spreading the nutrient load.

The accumulation of SCFA in the caeca of chickens given the C-1 restricted diet suggests more efficient caecal metabolism of nutrients which may not have been absorbed in the small intestine. If rate of transit through the gastrointestinal tract is increased as a result of intermittent feeding of a high-fibre diet, loss of nutrients may occur before intestinal absorption can take place which may lead, therefore, to enhanced caecal bacterial activity and caecal hypertrophy. Soluble fibres such as mixed-linked $\beta$-glucans are fermentable in the human colon (Cummings et al. 1987). In the present experiment, increased 
concentrations of propionate in caeca of chickens given BP diets in comparison with chickens receiving the $a d$ lib. $\mathrm{C}$ diet suggested that the relatively indigestible pectins may still be fermented in the caeca.

The nutritional effects of increased meal frequency were indicated in the observed reduction in plasma lipid concentrations and reduced postprandial triacylglycerol concentration. Inclusion of dietary pectins from sugar-beet pulp were concluded to reduce plasma lipid levels beneficially in particular, and inclusion of sugar-beet pulp in the chicken diets may assist in overcoming high plasma lipid concentrations associated with reduced meal frequency. Further work into the effect of meal frequency on insulin and the enzymes mediated by insulin coupled with a better understanding of changes in the gastrointestinal tract are required in determining the mechanisms underlying the hypercholesterolaemic response to gorging.

The authors gratefully acknowledge the technical assistance of members of the Division of Plant Products and staff members of the National Laboratory for Agricultural Chemistry. This work was supported financially by the Swedish Council for Forestry and Agricultural Research.

\section{REFERENCES}

Åman, P. \& Hesselman, K. (1984). Analysis of starch and other main constituents of cereal grains. Swedish Journal of Agricultural Research 14, 135-139.

Anderson, J. W., Deakins, D. A., Floore, T. A., Smith, B. M. \& Whitis, S. E. (1990). Dietary fiber and coronary heart disease. Critical Reviews in Food Science and Nutrition 29, 95-147.

Anderson, J. W. \& Tietyen-Clark, J. (1986). Dietary fiber: Hyperlipidemia, hypertension and coronary heart disease. American Journal of Gastroenterology 81, 907-919.

Anon (1971). Determination of crude oils and fats. Official Journal of the European Communities L297, 995-997.

Association of Official Analytical Chemists (1984). Official Methods of Analysis, 14th ed. Washington, DC: Association of Official Analytical Chemists.

Chang, M. L. W. (1983). Dietary pectin: effect on metabolic processes in rats. In Unconventional Sources of Dietary Fiber. ACS Symposium Series 214, pp. 143-154 [I. Furda, editor]. Washington, DC: American Chemical Society.

Cryer, A. (1987). Comparative biochemistry and physiology of lipoprotein lipase. In Lipoprotein Lipase, pp. 277-327 [J. Borensztajn, editor]. Chicago: Evener Publications.

Cummings, J. H., Pomare, E. W., Branch, W. J., Naylor, C. P. E. \& Macfarlane, G. T. (1987). Short-chain fatty acids in human large intestine, portal, hepatic and venous blood. Gut 28, 1221-1227.

Dietschy, J. M., Sallee, V. L. \& Wilson, F. A. (1971). Unstirred water layers and absorption across the intestinal mucosa. Gastroenterology 61, 932-934.

Fábry, P. \& Kujalová, V. (1960). Enhanced growth of small intestine in rats as a result of adaptation to intermittent starvation. Acta Anatomica 43, 264-271.

Fábry, P. \& Tepperman, J. (1970). Meal frequency - a possible factor in human pathology. American Journal of Clinical Nutrition 23, 1059-1068.

Fenton, T. W. \& Fenton, M. (1979). An improved procedure for the determination of chromic oxide in feed and feces. Canadian Journal of Animal Science 59, 631-634.

Flourie, B., Vidon, N., Florent, C. H. \& Bernier, J. J. (1984). Effect of pectin on jejunal glucose absorption and unstirred layer thickness in normal man. Gut 25, 936-941.

Furda, I. (1990). Interaction of dietary fiber with lipids-mechanistic theories and their limitations. In New Developments in Dietary Fiber, pp. 67-82 [I. Furda and C. J. Brine, editors]. New York: Plenum Press.

Graham, H., Hesselman, K. \& Aman, P. (1986). The influence of wheat bran and sugar-beet pulp on the digestibility of dietary components in a cereal-based pig diet. Journal of the Science of Food and Agriculture $\mathbf{4 2}$, $77-85$.

Jenkins, D. J. A., Ocana, A., Jenkins, A. L., Wolever, T. M. S., Vuksan, V., Katzman, L., Hollands, M., Greenberg, G., Corey, P., Patten, R., Wong, G. \& Josse, R. G. (1992). Metabolic advantages of spreading the nutrient load: effects of increased meal frequency in non-insulin dependent diabetics. American Journal of Clinical Nutrition 55, 461-467.

Jenkins, D. J. A., Wolever, T. M. S., Vuksan, V., Brighenti, F., Cunnane, S. C., Rao, A. V., Jenkins, A. L., Buckley, G., Patten, R., Singer, W., Corey, P. \& Josse, G. (1989). Nibbling versus gorging: metabolic advantages of increased meal frequency. New England Journal of Medicine 321, 929-934.

Johnson, I. T. \& Gee, J. M. (1981). Effect of gel-forming gums on the intestinal unstirred layer and sugar transport in vitro. Gut 22, 398-403. 
Kritchevsky, D. (1986). Dietary fiber and atherosclerosis. In Dietary Fiber: Basic and Clinical Aspects, pp. 265-312 [G. V. Vahouny and D. Kritchevsky, editors]. New York: Plenum Press.

Lampe, J. W., Slavin, J. L., Baglien, K. S., Thompson, W. O., Duane, W. C. \& Zavoral, J. H. (1991). Serum lipid and fecal bile acid changes with cereal, vegetable and sugar-beet feeding. American Journal of Clinical Nutrition 53, 1235-1241.

Michel, F., Thibault, J,-F. \& Barry, J.-L. (1988). Preparation and characterisation of dietary fibre from sugar beet pulp. Journal of the Science of Food and Agriculture 42, 77-85.

O'Looney, P. A. \& Vahouny, G. V. (1987). Diabetes and lipoprotein lipase activity. In Lipoprotein Lipase, pp. 229-246 [J. Borensztajn, editor]. Chicago: Evener Publications.

Pettersson, D. \& Åman, P. (1992). Production responses and serum lipid concentrations of broiler chickens fed diets based on oat bran and extracted oat bran with and without enzyme supplementation. Journal of the Science of Food and Agriculture 58, 569-576.

Pettersson, D. \& Razdan, A. (1993). Effects of increasing levels of sugar-beet pulp in broiler chicken diets on nutrient digestion and plasma cholesterol. British Journal of Nutrition 70, 127-137.

Quinn, D., Shirai, K. \& Jackson, R. L. (1982). Lipoprotein lipase: mechanism of action and role in lipid metabolism. Progress in Lipid Research 22, 35-78.

Sandhu, K. S., El Samahi, M. M., Mena, I., Dooley, C. P.\& Valenzuela, J. E. (1987). Effect of pectin on gastric emptying and gastroduodenal motility in normal subjects. Gastroenterology 92, 486-492.

Sellers, A. F. (1977). Genesis and propagation of motor activity in the digestive tract. In Duke's Physiology of Domestic Animals, pp. 233-239 [M. J. Swenson, editor]. New York: Ithaca.

Statistical Analysis Systems Institute Inc. (1985). SAS User's Guide: Statistics. Cary, North Carolina: SAS Institute Inc.

Theander, O.\& Westerlund, E. (1986). Studies on dietary fibers. 3. Improved procedures for analysis of dietary fibers. Journal of Agricultural and Food Chemistry 34, 330-336.

Vahouny, G. V. \& Cassidy, M. M. (1986). Dietary fiber and intestinal adaptation. In Dietary Fiber: Basic and Clinical Aspects, pp. 181-209 [G. V. Vahouny and D. Kritchevsky, editors]. New York: Plenum Press. 